\title{
C2-3 Fusion, C3-4 Cord Compression and C1-2 Posterior Facetal Instability: An Evaluation of Treatment Strategy Based on Four Surgically Treated Cases
}

\author{
Atul Goel \\ Department of Neurosurgery, K.E.M. Hospital and Seth G.S. Medical College, Parel, India
}

\begin{abstract}
Study Design: Four patients had C2-3 vertebral fusion and radiologically demonstrated cord compression at C3-4 level related to disc bulge with or without association of osteophytes and C1-2 posterior facetal dislocation. The outcome of treatment by atlantoaxial and subaxial facetal fixation is discussed.

Purpose: The article evaluates the significance of atlantoaxial facetal instability in cases having C2-3 vertebral fusion and cord compression at the level of $\mathrm{C} 3-4$ disc.

Overview of Literature: C2-3 vertebral fusions are frequently encountered in association with basilar invagination and chornic atlantoaxial dislocations. Even when basilar invagination and atlantoaxial dislocation are not identified by conventional parameters, atlantoaxial instability can be the nodal point of pathogenesis in cases with C2-3 vertebral fusion.

Methods: Between June 2013 and November 2014 four patients having C2-3 fusion presented with progressive symptoms of myelopathy that were related to cord compression at the level opposite the C3-4 disc space. Further investigations revealed C1-2 posterior facetal dislocation.

Results: All patients were males. Ages ranged from 18 to 50 years (average, 36 years). All patients were treated by atlantoaxial facetal plate and screw, and subaxial single or multi-segmental transarticular screw fixation. Follow-up (average, 15 months) using a recently described clinical grading system and the Japanese Orthopaedic Association scoring system confirmed marked improvement of symptoms.

Conclusions: Identification and treatment of atlantoaxial facetal instability may be crucial for a successful outcome in cases having C2-3 fusion and high cervical (C3-4) disc related cord compression.
\end{abstract}

Keywords: Atlantoaxial dislocation; High cervical disc prolapse; Transarticular fixation

\section{Introduction}

The author presents clinical details of four patients who had C2-3 vertebral body fusion and cord compression opposite the C3-4 disc space. All patients had posterior atlantoaxial facetal instability [1]. There was no radiographic evidence of odontoid process related instability as traditionally assessed by an increase in atlantodental in-

Received Sep 16, 2015; Revised Sep 17, 2015; Accepted Sep 17, 2015

Corresponding author: Atul Goel

Department of Neurosurgery, K.E.M. Hospital and Seth G.S. Medical College, Parel, Mumbai-400012, India

Tel: +91-22-24129884, Fax: +91-22-24143435, E-mail: atulgoel62@hotmail.com 
Table 1. Table showing the presenting demographic and radiological features

\begin{tabular}{|c|c|c|c|c|c|}
\hline Patient no. & $\begin{array}{l}\text { Sex/age } \\
\text { (yr) }\end{array}$ & Radiological findings & $\begin{array}{l}\text { Posterior atlantoaxial } \\
\text { instability }\end{array}$ & $\begin{array}{c}\text { Other } \\
\text { anomalies }\end{array}$ & Levels fixed \\
\hline 1. & Male/39 & $\begin{array}{l}\text { C2-3 fusion with cord compression } \\
\text { at C3-4 level }\end{array}$ & Present & - & $\begin{array}{l}\text { C1-2, C3-4 and } \\
\text { C4-5 }\end{array}$ \\
\hline 2. & Male/18 & $\begin{array}{l}\text { C2-3 fusion with cord compression } \\
\text { at C3-4, C4-5 and C5-6 levels }\end{array}$ & Present & $\begin{array}{l}\text { Occipitalization } \\
\text { of atlas }\end{array}$ & $\begin{array}{l}\text { C1-2, C3-4, C4-5 } \\
\text { and C5-6 levels }\end{array}$ \\
\hline 3. & Male/36 & $\begin{array}{l}\text { C2-3 fusion with cord compression } \\
\text { at C3-4 and C4-5 levels }\end{array}$ & Present & - & $\begin{array}{l}\text { C1-2, C3-4 and } \\
\text { C4-5 }\end{array}$ \\
\hline 4. & Male/50 & $\begin{array}{l}\text { C2-3 fusion with cord compression } \\
\text { at C3-4 and C4-5 levels }\end{array}$ & Present & $\begin{array}{l}\text { Bifid posterior } \\
\text { arch of atlas }\end{array}$ & $\begin{array}{l}\text { C1-2, C3-4 and } \\
\text { C4-5 }\end{array}$ \\
\hline
\end{tabular}

Table 2. Distribution as per our clinical grading system

\begin{tabular}{llcc} 
Grade & \multicolumn{1}{c}{$\begin{array}{c}\text { Description } \\
\text { No. of patients }\end{array}$} & $\begin{array}{c}\text { No. of patients } \\
\text { (postoperative) }\end{array}$ & $\begin{array}{c}\text { (preoperative) } \\
3\end{array}$ \\
\hline 1 & Independent and normally functioning & - & 2 \\
\hline 3 & Walks on own but needs support/help to carry out routine household activities & 2 & - \\
\hline 5 & Walks with minimal support and requires help to carry out household activities & - & - \\
\hline
\end{tabular}

terval or cord compression at the craniovertebral junction. Treatment by atlantoaxial and subaxial single or multisegmental facetal fixation resulted in remarkable recovery from symptoms of myelopathy. The treatment philosophy is discussed.

\section{Materials and Methods}

From June 2013 to November 2014, four patients presented with symptoms related to cervical myelopathy. Investigations revealed $\mathrm{C} 2-3$ vertebral fusion and predominant cord compression opposite C3-4 disc space. The four patients were evaluated.

\section{Results}

All patients were males. The demographic and radiological details are summarized in Table 1 . Our recently discussed clinical grading system (Table 2) [2] and Japanese Orthopaedic Association scoring system (Table 3) [3] were used to monitor neurological status both before and after surgery. Preoperative investigations included dynamic computed tomography (CT) scan, magnetic resonance imaging (MRI) and plain radiological images in flexion
Table 3. Table showing the preoperative and postoperative clinical assessment as per J0A scoring system

\begin{tabular}{lcc} 
JOA score & $\begin{array}{c}\text { Preoperative } \\
\text { (no. of patients) }\end{array}$ & $\begin{array}{c}\text { Postoperative } \\
\text { (no. of patients) }\end{array}$ \\
$<7$ & - & 4 \\
$8-12$ & 4 & - \\
$13-15$ & - & - \\
$16-17$ & - & - \\
\hline
\end{tabular}

JOA, Japanese Orthopaedic Association.

and extension neck position. Investigations showed no, insignificant or only marginal cord compression at the level of odontoid process (Fig. 1). The atlantodental interval was within the range of normal. Cervical imaging revealed $\mathrm{C} 2-3$ fusion and most prominent cord compression opposite C3-4 disc space. Moderate cord compression at C4-5 level was seen in 3 cases and opposite C5-6 level disc space in 1 case. On reviewing the CT and MRI slices focused on C1-2 facets, posterior atlantoaxial facetal (Type B) dislocation was evident in all cases [1] (Fig. 1). Additional radiological findings included occipitalization of the atlas in one case and presence of bifid posterior arch of atlas in one case. All patients underwent surgery 
by posterior cervical route in prone position. Cervical traction was applied after induction of anesthesia and prior to turning the patient. The head end of the table was elevated by 30 degrees. Head elevation allowed direct surgical access to the craniovertebral junction and reduced venous congestion in the operative field. Cervical traction was applied basically to keep the head steady during the conduct of surgery and keep the pressure off the face and eyes. Atlantoaxial fixation was done using lateral mass plate and screws with the technique described by us in $1994[4,5]$. The atlantoaxial joint was widely exposed. The articular cartilage was denuded using power driven drills and the joint cavity was stuffed with bone graft harvested from iliac crest. The $\mathrm{C} 2$ ganglion was either sectioned or was elevated superiorly to have a wide exposure of the field and to conduct the instrumentation. C3-4, C4-5, and C5-6 facets were exposed and inspected by physical manual handling. Instability of the facets was clearly identified during surgery at the C3-4 level. Additionally, facetal instability was observed in all four patients at the C4-5 level and in one patient at the C5-6 level. Of these cases, instability was identified and treated at the C4-5
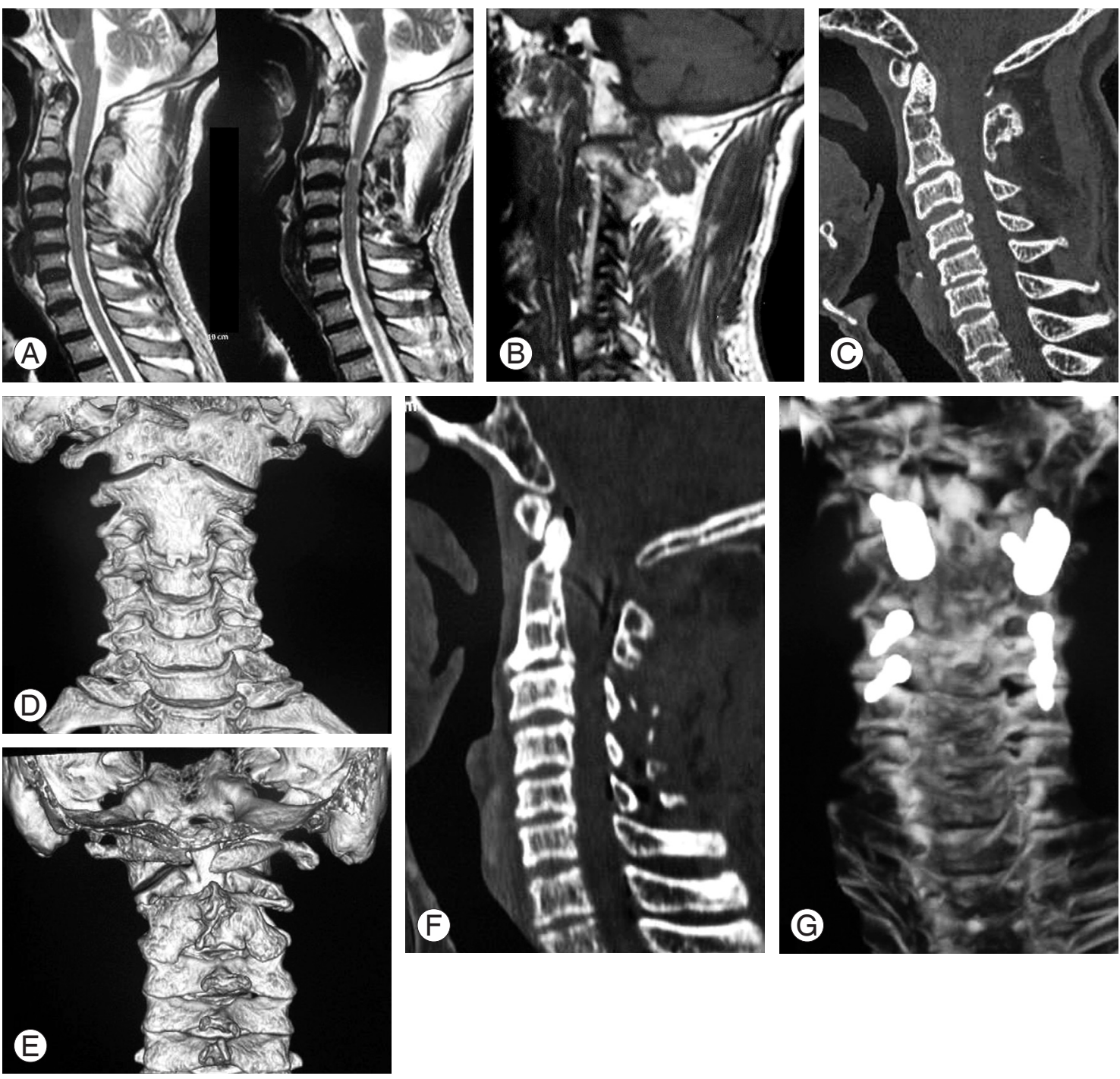

Fig. 1. Images of a 50-year-old male patient. (A) T2-weighted magnetic resonance imaging (MRI) shows C2-3 fusion and altered cord signal opposite C3-4 disc space. There is no evidence of any cord compression at the level of tip of odontoid process. (B) Sagittal cut of MRI at the level of facets showing Goel type B atlantoaxial facetal instability. (C) Computed tomography (CT) scan showing the C2-3 fusion. (D) Three-dimensional (3D) CT scan of the cervical spine showing the fusion of C2-3 vertebrae and the facets. (E) Posterior view of the 3D CT scan showing the bifid arch of atlas. (F) Postoperative CT scan findings. (G) Postoperative scan shows fixation of C1-2 (lateral mass plate and screw technique) and C3-4 and C4-5 by transarticular method of fixation. 
level in one case despite the fact that radiological images did not show significant cord compression at these levels. Transarticular screw fixation was done at all the subaxial levels by deploying recommended parameters [6]. A suitable size osteotome was introduced into the joint cavity with its flat edge and turned by 90 degrees in a screwing fashion to affect denuding of the articular cartilage. Transarticular fixation was then completed. Screws used for transarticular fixation averaged $2.7 \mathrm{~mm}$ in diameter and $14 \mathrm{~mm}$ in length. All the soft tissues and ligaments attached to the spinous process were sharply sectioned and removed. Spinous processes at the levels of surgery were sectioned at the base. Bone material of the spinous processes was meshed into thin pieces and placed over the midline and over the instrumented facets after appropriately preparing the host bone. Additional bone graft material was obtained from the iliac crest. Postoperatively, the patient used hard cervical collar for 8 weeks after surgery and neck movement was kept to a minimum. Postoperative investigations were done 3 weeks and 3 months after surgery. Subsequent imaging was done after one year. Follow-up for the four cases was at $6,12,18$, and 24 months. During follow-up, all patients improved significantly in neurological function (Tables 2, 3). There were no infection- or implant-related mechanical problems.

\section{Discussion}

C2-3 vertebral bone fusion is relatively a frequent observation in cases with craniovertebral instability in general and basilar invagination in particular. In 2009, we presented a series of 170 cases having basilar invagination and identified 44 cases having C2-3 vertebral fusion [7]. In the article, we concluded that musculoskeletal changes that included bone fusions were secondary to primary atlantoaxial instability. Increase in neck height, reversal of torticollis, reversal of platybasia and a number of other features that were associated with postoperative craniovertebral realignment were identified after the atlantoaxial joint was fixed and stabilized. We also discussed the potential of reversal of secondary osteophytic changes and bone fusions following atlantoaxial joint stabilization surgery.

C3-4 disc-related cord compression is frequently identified in cases with basilar invagination and atlantoaxial dislocation. In 2004 and 2008, we identified the association of basilar invagination and atlantoaxial instability and C3-4 disc related cord compression [8,9]. We discussed that craniovertebral junction instability was the primary pathology and cervical spondylotic changes in general and C3-4 disc disease in particular were secondary spinal alterations that are designed to affect shortening of the neck size. We suggested the need for atlantoaxial stabilization as the treatment for such a condition and advocated that there was no necessity of surgically dealing with the spinal spondylotic alterations $[8,9]$.

In the present cases, $\mathrm{C} 2-3$ vertebral body fusion and C3-4 disc-osteophyte-related cord compression were evident. There was no or insignificant basilar invagination. In one patient there was assimilation of atlas and in one case there was presence of bifid posterior arch of atlas. Both features suggested a more generalized spinal malformation that included a craniovertebral junctional anomaly. There was no evidence of cord compression or compromise of spinal canal dimensions related to odontoid process. Also, conventional dynamic flexion-extension imaging did not reveal any abnormal movements of the odontoid process that could suggest instability. As per our recently described classification of atlantoaxial facetal dislocation and instability [10], all patients had Type B dislocation, wherein the facet of atlas was dislocated posterior to the facet of axis. In our publications related to basilar invagination, Chiari malformation, syringomyelia and atlantoaxial dislocation, we identified that Type $\mathrm{B}$ and Type $\mathrm{C}$ or central or axial facetal dislocation (the facets are in alignment, but there is atlantoaxial instability that is identified and confirmed only during surgery) are associated with more chronic forms of craniovertebral anomalies $[2,11]$. The symptom complex is subtle and longstanding as there is no direct compression of the cord by the odontoid process. This is in variance with Type A facetal dislocation, wherein the facet of atlas is dislocated anterior to the facet of axis, a process that results in atlantoaxial dislocation and basilar invagination and posterior migration of odontoid process into the spinal canal and resultant cord compression. Despite the fact that there is no direct odontoid process related neural compression in Type $\mathrm{B}$ and Type $\mathrm{C}$ atlantoaxial facetal dislocation, the entire musculoskeletal and neural transformation that includes Chiari malformation and syringomyelia is related to atlantoaxial instability $[2,11]$. Atlantoaxial fixation results in relatively rapid reversal of neurological symptoms and potential or manifest reversal of all musculoskeletal and neural malformations [7]. We recently identified the presence of atlantoaxial facetal instability in cases with degenerative cervical spon- 
dyltoic myelopathy. Despite the fact that there was no cord compression related to odontoid process, we recommended atlantoaxial fixation in such cases and concluded that missing atlantoaxial instability in such cases can be a cause of failure of surgical treatment [1].

Although there are no morphological or radiological studies that discuss the relative alignment of facet of atlas and facet of axis, it does seem that some degree of malalignment may be in the range of normalcy. It appears that the facetal instability should be viewed in a wider perspective and clinical interpretations should be based on association of a number of other morphological and clinical factors. Our classification of atlantoaxial instability and basilar invagination based on the type of facetal malalignment, rather than the conventional evaluation of the region based on odontoid process related cord compression, presents an alternative format of understanding of instability at the craniovertebral junction. Drawing on our long-term experience spanning over 25 years and dealing with over 1,400 cases having instability of the atlantoaxial joint and treatment by direct manipulation of facets, we identified that there was evidence of marked instability of atlantoaxial joint in Types B and C dislocation. Stabilization of the atlantoaxial joint forms the basis of treatment.

In all four patients, there was evidence of Type B atlantoaxial facetal dislocation. The association of $\mathrm{C} 2-3$ fusion and C3-4 disc disease did not appear incidental in these cases. In all four cases, facetal fixation of C3-4 was done in addition to atlantoaxial fixation. As with our experience in cases with basilar invagination and high cervical discs wherein we suggested that only atlantoaxial fixation is sufficient and dealing with the cervical disc related cord compression is not necessary, it is unclear if only atlantoaxial fixation would have sufficed in the presented cases. Instability was identified by direct observations and manual handling of both atlantoaxial and C3-4 facets joint [12-16]. Stabilization resulted in remarkable recovery of symptoms that begun in the immediate postoperative phase and was progressive. Although our experience is limited, it does appear that ignoring of either of the unstable joints at $\mathrm{C} 1-2$ or at $\mathrm{C} 3-4$ could have adversely affected the clinical outcome. Despite our successful clinical outcome, it is clear that blinded analysis is required to assess the individual roles of atlantoaxial fixation and subaxial cervical spinal fixation. However, the relative rarity of such cases may make adoption of research protocols difficult.

\section{Conclusions}

Identification and treatment of atlantoaxial instability despite absence of odontoid process related cord compression can be a defining feature in success of surgical treatment in the complex clinical scenario of $\mathrm{C} 2-3$ bone fusion and C3-4 disc related cord compression.

\section{Conflict of Interest}

No potential conflict of interest relevant to this article was reported.

\section{References}

1. Goel A. Posterior atlantoaxial 'facetal' instability associated with cervical spondylotic disease. J Craniovertebr Junction Spine 2015;6:51-5.

2. Goel A. Is atlantoaxial instability the cause of Chiari malformation? Outcome analysis of 65 patients treated by atlantoaxial fixation. J Neurosurg Spine 2015;22: 116-27.

3. Fujiwara A, Kobayashi N, Saiki K, Kitagawa T, Tamai K, Saotome K. Association of the Japanese Orthopaedic Association score with the Oswestry Disability Index, Roland-Morris Disability Questionnaire, and short-form 36. Spine (Phila Pa 1976) 2003;28:1601-7.

4. Goel A, Desai KI, Muzumdar DP. Atlantoaxial fixation using plate and screw method: a report of 160 treated patients. Neurosurgery 2002;51:1351-6.

5. Goel A, Laheri V. Plate and screw fixation for atlantoaxial subluxation. Acta Neurochir (Wien) 1994;129: 47-53.

6. Roy-Camille R, Saillant G. Surgery of the cervical spine: 2. Dislocation. Fracture of the articular processes. Nouv Presse Med 1972;1:2484-5.

7. Goel A, Shah A. Reversal of longstanding musculoskeletal changes in basilar invagination after surgical decompression and stabilization. J Neurosurg Spine 2009;10:220-7.

8. Goel A. High cervical C3-4 'disc' compression associated with basilar invagination. Neurol India 2008;56:68-70.

9. Goel A, Phalke U, Cacciola F, Muzumdar D. Surgical management of high cervical disc prolapse associated with basilar invagination: two case reports. Neurol Med Chir (Tokyo) 2004;44:142-5. 
10. Goel A. Goel's classification of atlantoaxial "facetal" dislocation. J Craniovertebr Junction Spine 2014;5:38.

11. Goel A. Is Chiari malformation nature's protective "air-bag"? Is its presence diagnostic of atlantoaxial instability? J Craniovertebr Junction Spine 2014;5:1079.

12. Goel A. Facet distraction spacers for treatment of degenerative disease of the spine: rationale and an alternative hypothesis of spinal degeneration. J Craniovertebr Junction Spine 2010;1:65-6.

13. Goel A. Facet distraction-arthrodesis technique: Can it revolutionize spinal stabilization methods? J Cra- niovertebr Junction Spine 2011;2:1-2.

14. Goel A. Only fixation for cervical spondylosis: report of early results with a preliminary experience with 6 cases. J Craniovertebr Junction Spine 2013;4:64-8.

15. Goel A, Shah A, Gupta SR. Craniovertebral instability due to degenerative osteoarthritis of the atlantoaxial joints: analysis of the management of 108 cases. J Neurosurg Spine 2010;12:592-601.

16. Goel A, Shah A. Facetal distraction as treatment for single- and multilevel cervical spondylotic radiculopathy and myelopathy: a preliminary report. J Neurosurg Spine 2011;14:689-96. 